\title{
La tafonomía como marco metodológico para interpretar depósitos funerarios superficiales: estudio de la cueva sepulcral de El Espinoso (Ribadedeva, Asturias)*
}

\author{
Taphonomy as a methodological framework for understanding surface funerary deposits: \\ the human burial at the cave of El Espinoso (Ribadedeva, Asturias)
}

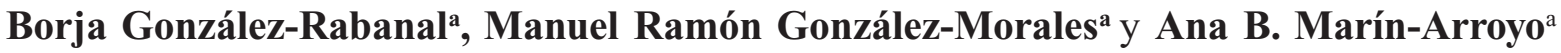

\section{RESUMEN}

Durante la Edad del Bronce en el norte de la Península Ibérica algunos grupos humanos inhumaban a sus congéneres sobre la superficie del suelo de cuevas de difícil acceso. Esta tradición cultural, muy arraigada en el País Vasco y en Cantabria, se extiende hasta la región oriental de Asturias. Este trabajo se centra en el estudio tafonómico de los restos humanos encontrados en 1993 en la cueva de El Espinoso (Ribadedeva, Asturias). La cueva fue utilizada como lugar de inhumación de un número mínimo de veinte individuos, de ambos sexos y diferentes edades. Este yacimiento constituye el único enterramiento múltiple en cueva de la Edad del Bronce documentado hasta ahora en Asturias, sumándose así a otros yacimientos de la Prehistoria Reciente de esta región, como son El Toral III, La Llana y Fuentenegroso y consolidando esta tradición funeraria a lo largo de dos mil años en el Oriente de Asturias. La tafonomía ha ofrecido un marco teórico y metodológico preciso para estudiar este tipo de yacimientos en superficie, afectados por complejos procesos post-deposicionales.

\begin{abstract}
During the Bronze Age the human groups of Cantabria buried their dead on the surface of narrow caves. This cultural tradition, common to the Basque Country and Cantabria, extends to eastern Asturias. This work focuses on the taphonomical study of the human remains found in 1993 in the cave of El Espinoso, located in Ribadedeva (Asturias). The cavity was used as a burial place for a minimum of twenty individuals of both sexes and different ages. This site constitutes the only collective burial cave currently known from the Bronze Age in Asturias (other later prehistoric burial caves in the region -El Toral III, La Llana, Fuentenegroso, etc.- have single burials). A funerary tradition of cave burial lasted over two thousand years in eastern Asturias. The taphonomical analysis provides a theoritical and methodological framework adequate to the study this type of superficial deposits, affected by complex post-depositional processes.
\end{abstract}

Palabras clave: Cueva sepulcral; Edad del Bronce; Cueva de El Espinoso; Enterramiento múltiple; Oriente de Asturias.

Key words: Burial cave; Bronze Age; El Espinoso cave; collective burial; eastern Asturias.

* Este estudio se ha realizado a partir del Trabajo Fin de Máster del primero de los autores. La investigación ha sido apoyada por el Instituto Internacional de Investigaciones Prehistóricas de Cantabria y financiada por el Proyecto "Tracing Climatic Abrupt Change Events and Their Social Impact during the Late Pleistocene and Early Holocene (15-7 ky calBP) (HAR2013-46802-P)" financiado por el Ministerio de Economía y Competitividad de España.

${ }^{a}$ Instituto Internacional de Investigaciones Prehistóricas de Cantabria, Departamento de Ciencias Históricas, Universidad de Cantabria, Edificio Interfacultativo, Avda. Los Castros s/n. 39005 Santander, España. Correos e.: borjagrabanal@gmail.com http:// orcid.org/0000-0002-1802-994X ; moralesm@unican.es http://orcid.org/0000-0001-7277-7837 ; anabelen.marin@unican.es http://orcid. org/0000-0003-3353-5581.

Recibido 6-IX-2016; aceptado 2-XII-2016.

Copyright: (C) 2017 CSIC. Este es un artículo de acceso abierto distribuido bajo los términos de una licencia de uso y distribución Creative Commons Attribution (CC-by) España 3.0. 


\section{INTRODUCCIÓN}

\section{El yacimiento}

La Cueva de El Espinoso se encuentra en la costa central de la Región Cantábrica, en el Oriente de Asturias, en la localidad de La Franca (Ribadedeva) (Fig.1). Se levanta en un acantilado calizo de unos $30 \mathrm{~m}$ de altura que domina un valle ciego, próximo a la desembocadura del río Cabra, y a escasos $200 \mathrm{~m}$ del mar. El acceso es algo dificultoso por la pendiente que caracteriza este ambiente calizo, siendo necesario escalar una pared vertical de unos $4 \mathrm{~m}$ de altura. La entrada, orientada al $\mathrm{SO}$, es alta y amplia con un vestíbulo de unos 10 metros de longitud al que llega la luz solar. Al fondo del mismo hay un importante yacimiento arqueológico paleolítico, descubierto en 1978 por uno de los firmantes (MRGM) y su equipo (González Morales 1995). De este lugar parte una galería que vira al norte, reduciéndose en altura y anchura paulatinamente hasta una gatera que da acceso, arrastrándose, a la sala de pequeñas dimensiones que albergaba los restos humanos que se estudian en este tra-

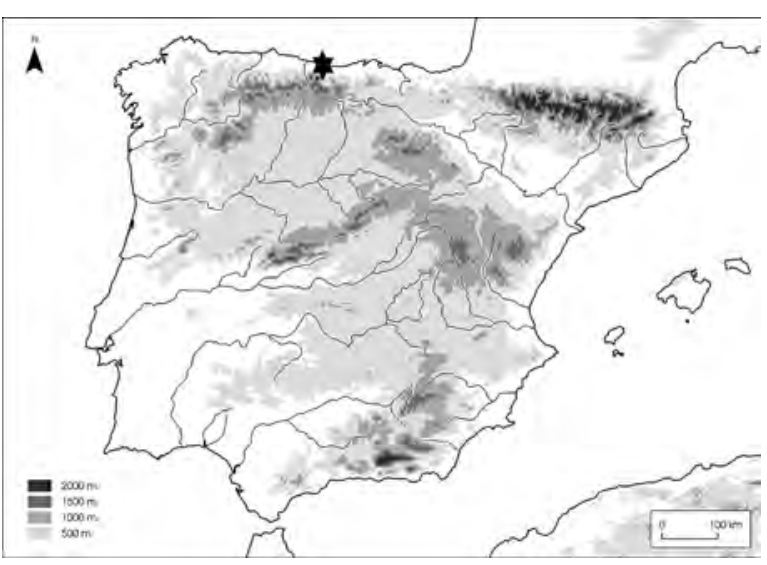

Fig. 1. Localización geográfica de la cueva de El Espinoso (Ribadedeva, Asturias) en la Región Cantábrica.

bajo. La denominada Sala de los Muertos tiene $40 \mathrm{~m}^{2}$ divididos en tres áreas: los Sectores A y $\mathrm{B}$, bajas y estrechas galerías, caracterizadas por la presencia de nichos naturales, estalactitas, estalagmitas, coladas y columnas estalagmíticas y el Sector C, dominado por pequeñas hornacinas, que sigue el margen izquierdo de la sala hasta el final (Fig. 2).

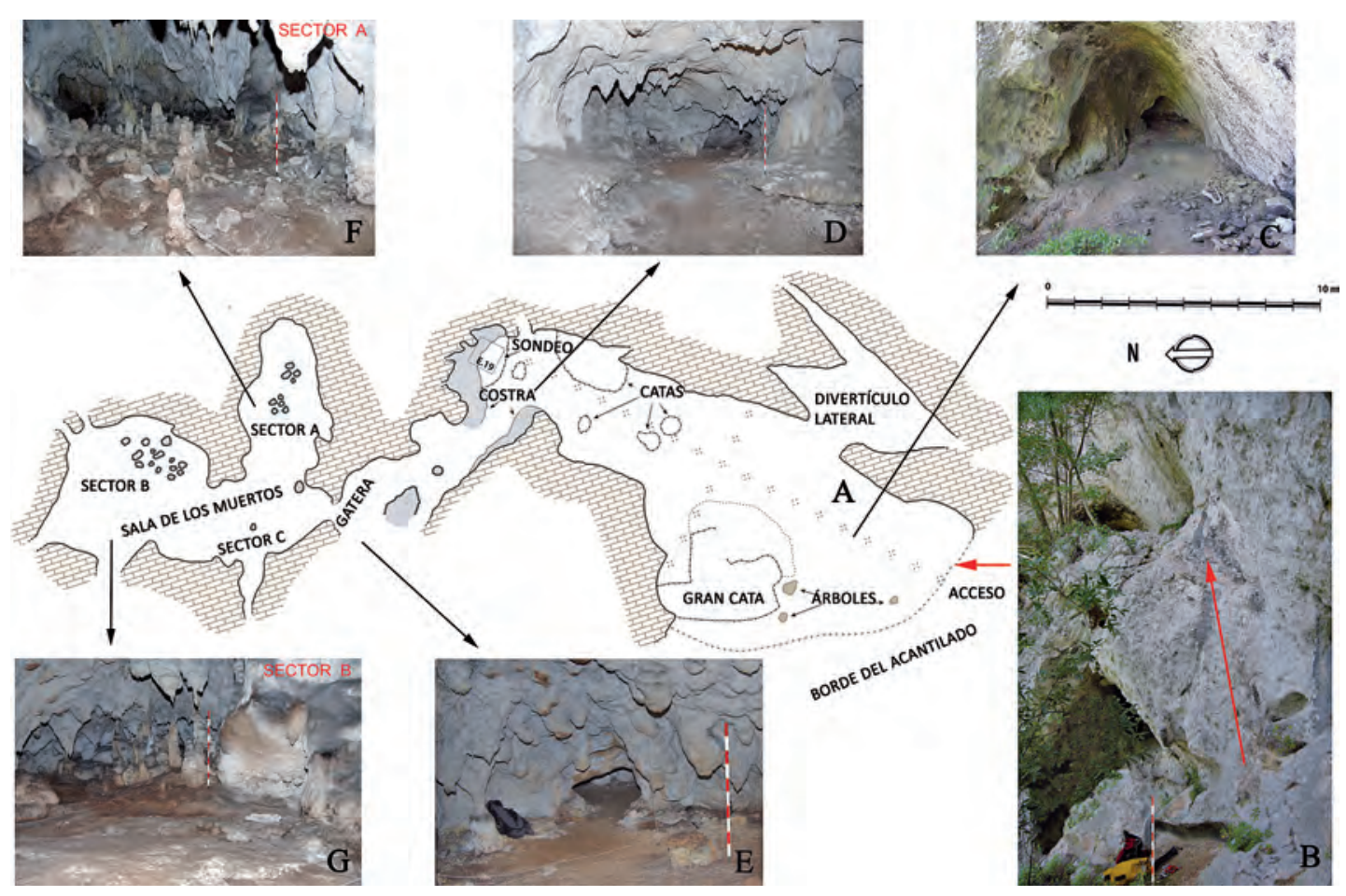

Fig. 2. Plano de la cueva de El Espinoso (A) e ilustraciones de sus diferentes zonas. B. acceso: la flecha roja señala la boca de entrada; C. vestíbulo; D. galería; E. gatera; F. Sala de los Muertos, Sector A; G. Sala de los Muertos, Sector B. Plano y fotos en color en la edición electrónica. 


\subsection{Historia de las investigaciones}

En 1979 y 1980 en dos breves campañas se excavó un sondeo en el yacimiento paleolítico y se documentaron numerosos restos humanos distribuidos sobre toda la superficie del suelo de la Sala de los Muertos, sin aparente conexión anatómica, muy fragmentados y algunos además muy concrecionados. Se fotografiaron ambos yacimientos pero se decidió excavar solo el primero que era el objetivo inicial de la investigación.

Durante una visita a la cueva en 1993 se identificaron varias catas y remociones de los materiales debidos a excavadores furtivos. En ese momento, se decidió excavar de urgencia el depósito sepulcral retirando los huesos en superficie si bien se apreció que otros surgían del interior del paquete de sedimentos, donde aún permanecen. En las campañas de 1979-80 y 1993 no se identificó ningún ajuar con los muertos. En cambio se conoce una serie de adornos de bronce, actualmente en paradero desconocido, relacionados con las alteraciones antrópicas modernas sufridas en ese lapso de tiempo. Se trata de tres brazaletes, un anillo y dos fragmentos de bronce (Fig. 3) ${ }^{1}$. En 2013 y 2014, a raíz de dos trabajos de investigación, se realizaron tres dataciones radiocarbónicas, dos de ellas correspondientes al yacimiento

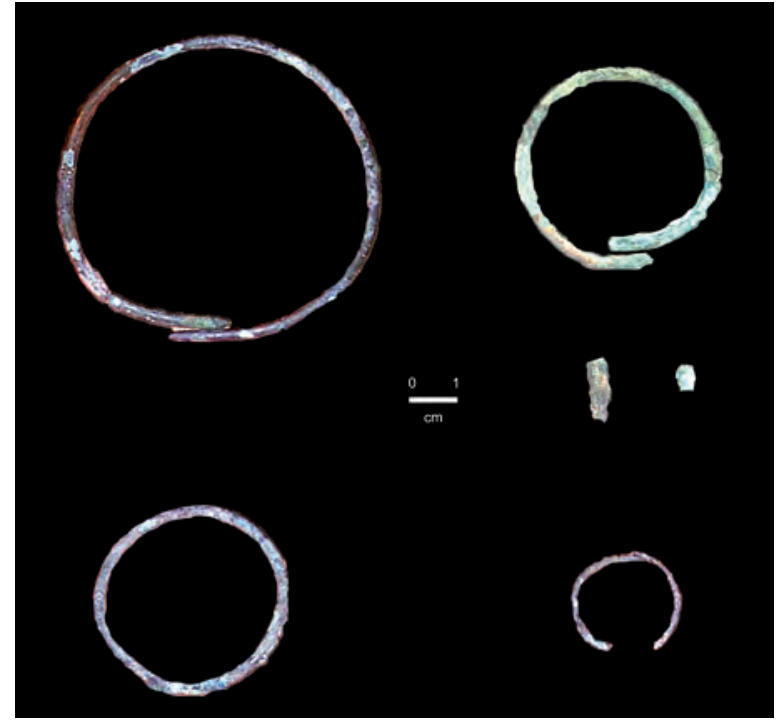

Fig. 3. Brazaletes y anillo de bronce, procedentes de remociones modernas en la cueva de El Espinoso (en color en la edición electrónica).

paleolítico y otra al depósito funerario (Cuenca Solana 2013: 251;2) (Tab. 1).

El estudio del depósito sepulcral de El Espinoso se hizo en 2014 y proporcionó 1230 restos humanos (Tab. 2), 33 de fauna y 1175 huesos no identificables. En total se han estimado 732

\begin{tabular}{|l|c|c|c|c|c|c|}
\hline \multicolumn{1}{|c|}{ Yacimiento } & $\begin{array}{c}\text { Atribución } \\
\text { cultural }\end{array}$ & $\begin{array}{c}\text { Referencia } \\
\text { laboratorio }\end{array}$ & Fecha BP & $\begin{array}{c}\text { Fecha cal. } \\
\text { BC } \mathbf{1} \sigma\end{array}$ & Material & Referencia \\
\hline El Toral III & Neolítico & $\begin{array}{c}\text { UGAMS- } \\
5399\end{array}$ & $\begin{array}{c}4690 \pm 30 \\
\text { BP }\end{array}$ & $\begin{array}{c}3460 \pm 60 \mathrm{cal} . \\
\text { BC }\end{array}$ & $\begin{array}{c}\text { Hueso } \\
\text { humano }\end{array}$ & Noval Fonseca 2014 \\
\hline La Llana & Bronce & $\begin{array}{c}\text { UGAMS- } \\
9083\end{array}$ & $\begin{array}{c}3300 \pm 25 \\
\mathrm{BP}\end{array}$ & $\begin{array}{c}1576 \pm 35 \mathrm{cal} . \\
\mathrm{BC}\end{array}$ & $\begin{array}{c}\text { Hueso } \\
\text { humano }\end{array}$ & $\begin{array}{c}\text { Inédito González } \\
\text { Morales }\end{array}$ \\
\hline El Espinoso & Bronce & $\begin{array}{c}\text { ICA- } \\
14 \mathrm{~T} / 0804\end{array}$ & $\begin{array}{c}2960 \pm 40 \\
\mathrm{BP}\end{array}$ & $\begin{array}{c}1189 \pm 66 \mathrm{cal} . \\
\mathrm{BC}\end{array}$ & $\begin{array}{c}\text { Diente } \\
\text { humano }\end{array}$ & $\begin{array}{c}\text { Inédito González } \\
\text { Rabanal }\end{array}$ \\
\hline Fuentenegroso & Hierro & $\begin{array}{c}\text { BETA- } \\
166077\end{array}$ & $\begin{array}{c}2550 \pm 40 \\
\mathrm{BP}\end{array}$ & $\begin{array}{c}690 \pm 92 \mathrm{cal} . \\
\mathrm{BC}\end{array}$ & $\begin{array}{c}\text { Hueso } \\
\text { humano }\end{array}$ & Barroso et al. 2007 \\
\hline
\end{tabular}

Tab. 1. Dataciones radiocarbónicas en restos humanos de cuevas sepulcrales de la región oriental de Asturias. Calibradas con OxCal conforme a la curva IntCal13 (Reimer et al. 2013).

\footnotetext{
${ }^{1}$ Se acaban de iniciar los trámites para la recuperación de estos materiales arqueológicos, su estudio exhaustivo y depósito final en el museo regional.
} 
elementos humanos y un número mínimo de 20 individuos: 17 a partir del astrágalo y 3 del estudio dental de tres individuos infantiles. La población

\begin{tabular}{|c|c|c|c|}
\hline ELEMENTO ANATÓMICO & NR & NME & NMI \\
\hline Cráneo & 138 & 9 & 5 \\
\hline Maxilar & 6 & 4 & 4 \\
\hline Mandíbula & 7 & 6 & 5 \\
\hline Dientes & 147 & 147 & 11 \\
\hline Hioides & 2 & 2 & 2 \\
\hline Vértebra cervical & 22 & 22 & \\
\hline Vértebra torácica & 21 & 21 & \\
\hline Vértebra lumbar & 8 & 8 & \\
\hline Vértebras indeterminadas & 56 & & \\
\hline Sacro-cóccix & 21 & 8 & 8 \\
\hline Pelvis & 18 & 4 & 4 \\
\hline Costillas & 42 & 40 & \\
\hline Escápula & 13 & 13 & 5 \\
\hline Clavícula & 4 & 4 & 4 \\
\hline Esternón & 3 & 2 & 2 \\
\hline Húmero & 37 & 14 & 13 \\
\hline Cúbito & 30 & 12 & 12 \\
\hline Radio & 19 & 7 & 5 \\
\hline Carpales & 37 & 37 & 8 \\
\hline Metacarpos & 17 & 17 & 6 \\
\hline Falanges de mano & 85 & 85 & \\
\hline Fémur & 39 & 10 & 10 \\
\hline Rótula & 21 & 21 & 15 \\
\hline Tibia & 25 & 10 & 9 \\
\hline Peroné & 10 & 5 & 4 \\
\hline Tarsales & 42 & 42 & 11 \\
\hline Calcáneo & 22 & 22 & 14 \\
\hline Astrágalo & 25 & 24 & 17 \\
\hline Metatarsos & 42 & 42 & 11 \\
\hline Falanges de pie & 30 & 29 & \\
\hline Falanges indeterminadas & 65 & 65 & \\
\hline Indeterminado & 176 & & \\
\hline Total & 1.230 & 732 & $17+3$ \\
\hline
\end{tabular}

Tab. 2. El Espinoso: Número de Restos (NR), Número Mínimo de Elementos (NME) y Número Mínimo de Individuos (NMI) de cada elemento anatómico. consta de 6 niños (2 entre 0-3 años; 4 entre 3-12 años), 5 adolescentes, 7 adultos y 2 ancianos de ambos sexos ( 7 masculinos, 6 femeninos, 6 individuos infantiles no determinados y 1 individuo no identificable). La estatura media estimada de los adultos es $1,60 \mathrm{~m}$ para las mujeres y $1,71 \mathrm{~m}$ para los hombres ${ }^{3}$.

\section{ESTADO DE LA CUESTIÓN}

La tradición funeraria de depositar los muertos sobre la superficie de cuevas de pequeñas dimensiones predominó entre los grupos humanos de la Región Cantábrica durante el Calcolítico y la Edad del Bronce. No obstante, se conocen yacimientos de similares características desde el Neolítico hasta la Edad Media (Armendáriz 1990; Valle et al. 1996; Barroso et al. 2007; Hierro Gárate 2011). Estas denominadas "cuevas sepulcrales" incluso a veces son simples oquedades en la roca caliza, donde se deposita un número variable de individuos. Suelen estar formadas por galerías pequeñas, techos bajos y accesos a menudo difíciles bien por levantarse en escarpadas paredes calizas por las que hay que trepar, bien por tener una boca reducida. Cuando las inhumaciones se documentan en cuevas de habitación o de mayores dimensiones, lo habitual era elegir los lugares más reducidos y lóbregos de las mismas (Armendáriz y Etxeberría 1983: 331-336).

El sistema de inhumación consiste mayoritariamente en la deposición de los cadáveres sobre la superficie sin fosas, estructuras perimetrales o de cubrición, ni alteración artificial del suelo. En ocasiones, se utilizan simplemente las zonas de estas cavidades más reducidas y protegidas, como las paredes o los nichos naturales de la roca, o ni siquiera como si bastara la propia morfología de la cueva (Armendáriz 1990).

Los enterramientos (simples deposiciones) son colectivos, entendiendo como tales las inhumaciones de tres o más individuos. En Asturias, únicamente El Espinoso supera ampliamente la decena de inhumaciones, aunque El Bufón y Trespando tienen restos humanos pertenecientes a varios individuos y en las de La Llana o Fuentenegroso

\footnotetext{
3 Véase n. 2.
} 
las inhumaciones son individuales. En muchas de ellas se constata el reagrupamientos de los huesos más identificables (cráneo y huesos largos) y remociones o movimientos de las osamentas para liberar espacio para la deposición de nuevos cadáveres, vinculadas con la inhumación primaria sucesiva, práctica conocida en cuevas funerarias de esta época en las Islas Baleares y el País Valenciano (Lull et al. 1999; Soler Díaz y Roca de Togores 2012; Soler Díaz et al. 2016). Otras remociones se deben a distintos agentes tafonómicos (Armentano i Oller et al. 2012: 112-119). Sin embargo, lo más notable es el posible uso de andamios más o menos sofisticados u otro tipo de sistemas que izando o arriando los cuerpos mediante cuerdas los hiciera llegar a las cuevas más inaccesibles o impenetrables (Ontañón 2003). Es decir, esta tradición funeraria pretende proteger a los muertos del exterior, actuando el interior como "cueva-templo" (Soler Díaz y Roca de Togores 2012: 214-215).

Se han documentado más de 300 cuevas sepulcrales de la Edad del Bronce en la región cantábrica con núcleo en las actuales comunidades autónomas del País Vasco y Cantabria (160 y 180 cuevas respectivamente, frente a las 7 asturianas) (Arias Cabal y Armendáriz 1998: 69). El descenso cuantitativo de las mismas a medida que se avanza hacia el Oeste se ha conectado con algún tipo de frontera o barrera cultural entre las poblaciones de este periodo. Sin embargo merecen considerarse variables geológicas como el fin de las formaciones de roca caliza en la cuenca central de Asturias y la alteración tafonómica de los depósitos superficiales, así como otras vinculadas a la investigación. Entre ellas están la mayor labor prospectiva en el País Vasco y Cantabria desde décadas tempranas, la gran abundancia en el Oriente de Asturias de yacimientos paleolíticos y mesolíticos que han monopolizado la investigación a lo largo del siglo XX, la revisión de los yacimientos excavados en épocas antiguas o los nuevos estudios arqueológicos modernos.

En Asturias, las cuevas sepulcrales del Calcolítico y la Edad del Bronce mencionadas en la bibliografía son siete. La Cueva de El Bufón (Vidiago, Llanes) excavada a principios del siglo XX proporcionó cuatro cráneos con otros materiales arqueológicos. Son conocidas las inhumaciones individuales de Fuentenegroso (Sierra del Cuera) y La Llana (Llanes, estudio antropológico actualmente en curso), los restos humanos de El Toral III (Llanes) ${ }^{4}$, las cuevas de El Cuélebre y Trespando (Cangas de Onís) y la Cueva de El Espinoso (Ribadedeva) que estudiamos aquí. Únicamente se han realizado dataciones (Tab. 1) en las de El Toral III, La Llana, Fuentenegroso y El Espinoso (Arias Cabal et al. 1986; Ontañón 2003; Barroso et al. 2007; Noval Fonseca 2014; ${ }^{5}$. Se tienen vagas y muy antiguas referencias de hallazgos de restos humanos junto a materiales metálicos y cerámicos de diversa índole en la Cueva de la Fenoyal (Proaza), la Cueva del Palacio o del Pelagón (Grado), la Cueva de Valdediós (Villaviciosa) y el Abrigo de Valle (Piloña). Desafortunadamente, de la gran mayoría de ellas se desconoce el paradero de sus materiales. Algunos son hallazgos descontextualizados y aislados y otros se perdieron en el incendio de 1934 en la Universidad de Oviedo (Blas Cortina 1983).

Además hay restos humanos procedentes de otros contextos arqueológicos como las minas prehistóricas de cobre de El Aramo (Riosa) donde se hallaron entre 22 y 29 individuos y de El Milagro (Onís) con 4 individuos. Estas minas se sitúan en la transición Bronce Antiguo-Bronce Pleno y sus inhumaciones estarían relacionadas con la tradición de sepultar a los mineros que extraían el mineral en áreas ya explotadas, de poco tránsito o marginales de su medio de trabajo (Blas Cortina 2011: 745-747, 2014: 74-76).

Una primera conclusión se puede extraer sobre el fenómeno de las cuevas sepulcrales en Asturias: su precariedad y la escasez del registro. Se desconoce el paradero de algunos restos, otros no se han estudiado $\mathrm{y}$, sobre todo, el número de cavidades de uso funerario en esta época es muy reducido en comparación con las citadas en Cantabria y el País Vasco.

\footnotetext{
${ }^{4}$ González-Rabanal, B.: "Estudio preliminar de los restos humanos recuperados en la cueva de El Toral III (Asturias, Llanes)". En Arqueología en 3D: Herramienta social, Agente histórico y Ciencia natural. Libro de resúmenes. IX Jornadas de Jóvenes en Investigación Arqueológica. Santander 8-11 junio 2016: 50-51.

5 Véase n. 2.
} 


\section{METODOLOGÍA}

\subsection{Introducción}

La Tafonomía nace como concepto en la década de los 1940, acuñado por el paleontólogo soviético Iván Antónovitch Efremov (1940), para describir los procesos que afectan a los restos orgánicos en su transición desde la biosfera a la litosfera. Es decir, la Tafonomía se encarga de reconstruir las "leyes del enterramiento". Estos procesos abarcan todo lo relacionado con la manipulación, transporte, descomposición, transformación, conservación, desgaste y cualquier tipo de alteración (natural o antrópica) de los restos bióticos desde su muerte biológica hasta su total fosilización y descubrimiento (Reverte 1991). La Tafonomía considera procesos bioestratinómicos y diagenéticos. Los primeros se refieren a las circunstancias que ocurren entre la muerte del ser vivo y su enterramiento, es decir, en el tiempo peri-mortem de los restos. Los diagenéticos atañen a los efectos de todas las modificaciones que se producen desde el enterramiento hasta la recuperación de los restos enterrados. Müller (1951, 1963) concibió la bioestratinomía y la diagénesis como dos fases diferentes del proceso tafonómico, pero ya Weigelt (1927) había formulado el concepto de bioestratinomía. El concepto de diagénesis fue inicialmente utilizado en Geología para explicar la formación de las rocas sedimentarias a partir de la cementación de sedimentos sueltos. Pronto comenzaría a incorporarse a otras disciplinas como la Paleontología. En este contexto de expansión, Müller (1951, 1963) acuñaría el término de fosildiagénesis para explorar la historia post-enterramiento de los restos orgánicos.

Al principio el ámbito de aplicación de la Tafonomía se limitaba a la Paleontología, pero desde los 1960 comienza a expandirse y a emplearse en estudios arqueológicos de autores anglosajones como Behrensmeyer, Shipman o Andrews, consolidándose como una herramienta al servicio de la Arqueología a partir de los 1980 (Davidson y Estévez 1986). En las décadas finales del siglo XX una corriente profunda de experimentación desarrolla paulatinamente la metodología tafonómica en la Zooarqueología, aunque hasta la entrada del nuevo milenio no se utilizará de modo sistemático en la península ibérica (Quesada 2003 [1997]; ; Yravedra Sainz de los Terreros 2001; ; MarínArroyo 2010; Sala 2012) y su aplicación aún es escasa en restos humanos (Andrews y Fernández Jalvo 1997; Solari Giachino 2010; Esparza Arroyo et al. 2012; Armentano i Oller 2014; MarínArroyo 2015) sobre todo en cronologías holocenas y en yacimientos cantábricos.

Gran cantidad de agentes tafonómicos pueden afectar a la superficie de los huesos y, por tanto, a su conservación, desde los procesos físicos, químicos y biológicos hasta los fenómenos antrópicos relacionados con la manipulación humana (directa o indirecta) de esos restos (Fernández-Jalvo y Andrews 2016). En este trabajo se analizarán los agentes tafonómicos bioestratinómicos y diagenéticos que han afectado al depósito sepulcral de la cueva de El Espinoso, describiendo las diferentes tipologías y grados de alteración de cada proceso.

\subsection{Unidades de cuantificación}

El análisis de un conjunto óseo requiere de la cuantificación de todos los restos, identificables o no, según una serie de parámetros que permitan extrapolar los resultados. Para ello se han empleado el Número de Restos (NR), el Número Mínimo de Elementos (NME) y el Número Mínimo de Individuos (NMI) (Lyman 1994a: 42-44). Además se han aplicado dos índices para conocer el grado de fragmentación y conservación de cada elemento óseo y del total de la muestra: la Tasa de Fragmentación (TF) y el Índice de Representación Anatómica (IRA). La TF relaciona el NR y el NME. Se mide por referencia al valor 1: cuanto mayor es el resultado respecto a 1, mayor es el índice de fragmentación de los huesos (MarínArroyo 2010: 59). El IRA calcula la representación de cada hueso en el total de la muestra, basándose en la ratio entre el Número de Huesos Representados (NHR) y el Número de Huesos

\footnotetext{
${ }^{6}$ Martínez Moreno, J. 1998: La subsistencia de los grupos humanos del Paleolítico Medio: caza, tafonomía y recursos naturales. El ejemplo cantábrico y el catalán. Tesis doctoral. Universidad Autónoma de Barcelona.

${ }^{7}$ Mateos, A. 2005: Comportamientos de subsistencia y nicho ecológico de los grupos cazadores recolectores del occidente asturiano en el final del Pleistoceno. Tesis doctoral. Universidad de Salamanca.
} 
Esperados (NHE), teniendo en cuenta el Número Mínimo de Individuos (Bello y Andrews 2006: 2).

\subsection{Procesos tafonómicos bioestratinómicos y diagenéticos}

\subsubsection{Fracturación}

La fracturación de un conjunto óseo puede ocurrir durante la biostratinomía y la diagénesis o ante-mortem, en el momento de su enterramiento (peri-mortem) o después (post-mortem antiguas o recientes). Algunos autores han diferenciado fracturación y fragmentación, otorgando a cada una bien un origen antrópico o biológico, bien natural (Brugal 1994; Mateos 2003). En este trabajo se engloban bajo el concepto de "fracturación" las fracturas bioestratinómicas o diagenéticas. Adicionalmente, también la fracturación nos informa sobre sus orígenes biológicos (antrópico o por otros agentes) o físico-químicos. La fracturación de los restos óseos de El Espinoso se ha estudiando según el método de Vila y Mahieu (1991) que analiza el tipo, ángulo, perfil, borde y circunferencia de la fractura en huesos largos.

\subsubsection{Termoalteraciones}

Otras alteraciones tafonómicas, en general de origen antrópico, son las termoalteraciones, identificadas en los huesos a partir de coloraciones, texturas, fracturas, estrías e incluso deformaciones. Para la correcta interpretación del papel del fuego en yacimientos funerarios se analizan el estado de los huesos cuando se exponen al fuego y la temperatura que alcanzaron durante la combustión. Las termoalteraciones durante la bioestratinomía del conjunto fósil pueden ser "en fresco", cuando los huesos aún conservaban los paquetes musculares, o "en seco" a lo largo de la diagénesis, cuando los huesos están totalmente esqueletizados (Fernández-Crespo 2016: 130).

La coloración superficial de un elemento óseo cambia al alcanzar una temperatura elevada según distintos condicionantes. Algunos de ellos son la potencia calorífica que se reciba, la proximidad del sujeto a la fuente de calor, el tiempo de ex- posición, las variaciones de temperatura durante la exposición, la parte anatómica y la masa corporal del sujeto (Botella et al. 1999: 147-148). Los grados de coloración están intrínsecamente relacionados con la temperatura a la que estuvo sometido el elemento. Si no llega a los $300^{\circ} \mathrm{C}$, el color empezará a variar hacia tintes rojizos, tipo ocre, hasta llegar al marrón. La textura comenzará a ser más friable. Entre los $300^{\circ} \mathrm{C}-350^{\circ} \mathrm{C}$ los huesos se irán acercando a coloraciones cada vez más negras, comenzando su carbonización. Entonces empiezan a aparecer las estrías y las pequeñas fracturas debidas a la contracción de la materia orgánica. Si la temperatura excede los $500^{\circ} \mathrm{C}$ el hueso adquirirá un color grisáceo, llegando a blanco a partir de $\operatorname{los} 650^{\circ} \mathrm{C}$, inicio del proceso de incineración (Etxeberría 1994: 114).

En El Espinoso se han establecido tres tipologías de quemado según la coloración: marrón, negra y negruzca por contacto con carbones o sedimentos quemados (Fig. 4).

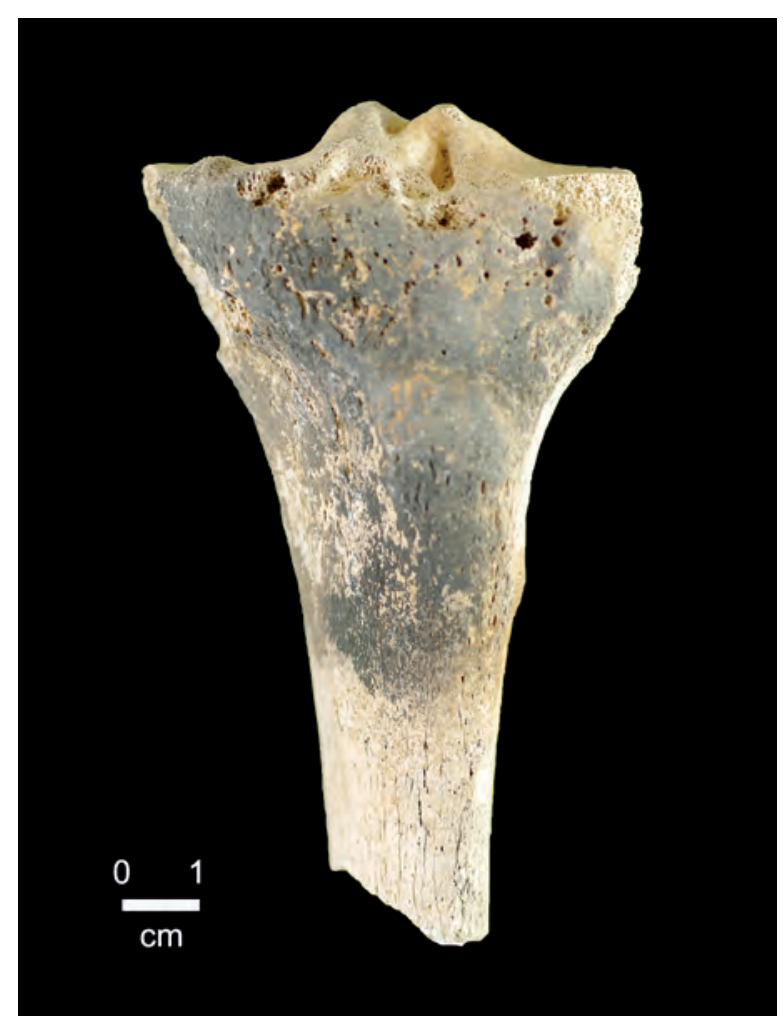

Fig. 4. Tipología de quemado por contacto con carbones o tierra quemada en fragmento de tibia humana procedente de El Espinoso (en color en la edición electrónica). 


\subsubsection{Marcas de carnívoros}

La tipología de la actividad de carnívoros identificada en El Espinoso se ha categorizado en punciones, mordisqueo y arrastres a partir de distintos autores (Binford 1981; Pérez Ripoll 1992; Lyman 1994b).

\subsubsection{Pisoteo}

Cualquier ser vivo (ya sea humano o animal) puedo provocar un proceso de pisoteo o trampling que resulta en distintas alteraciones sobre los huesos. Estas pueden ser espaciales, y modifican la posición primaria de los restos, o físicas como fracturas, pulidos y sobre todo estriaciones. Estas son longitudinales y se forman por el contacto directo de los huesos con los sedimentos, piedras u otros huesos, al ser pisoteados; según el sedimento sea más grueso o más fino las estrías serán mayores o menores, aunque no existen grandes cambios. Se han podido confundir con marcas de corte en algunas ocasiones, pero estudios experimentales recientes demuestran una total diferenciación (Domínguez-Rodrigo et al. 2009; Gaudzinski-Windheuser et al. 2010). Las marcas de pisoteo aparecen en cualquier parte del hueso, y son más finas y superficiales que las marcas de corte que, en general, se localizan en las mismas partes anatómicas y son más profundas. El efecto del pisoteo varía en cada hueso. Los huesos largos son más proclives a esta alteración que los cortos, como los tarsales o carpales, que apenas sufren modificación. Además, las alteraciones por pisoteo pueden ser tanto bioestratinómicas como diagenéticas (Olsen y Shipman 1988).

\subsubsection{Meteorización}

La meteorización o weathering es un proceso diagenético físico-químico que destruye los componentes orgánicos e inorgánicos del hueso (Behrensmeyer 1978: 153). Se produce por cambios bruscos de temperatura y humedad o por el contacto con ambientes encharcados muy presentes en contextos kársticos. También la luz solar, el viento y otros meteoros pueden contribuir a la paulatina destrucción de los huesos (Andrews y Whybrow 2005). Tampoco es descartable el tipo de terreno sobre el que se asientan los restos y el tiempo transcurrido. Las modificaciones que produce sobre el hueso son agrietamiento, escisión, exfoliación, deshidratación, y finalmente, desintegración.

El estudio de los grados de meteorización en los depósitos arqueológicos puede informar acerca de la ocupación del sitio, de las condiciones locales del yacimiento o del carácter sincrónico o diacrónico del registro, así como del tiempo que ha permanecido expuesto el conjunto óseo sobre la superficie tras su muerte (Lyman y Fox 1989). Sin embargo, los diferentes tipos de climas pueden favorecer o inhibir unos $\mathrm{u}$ otros estadios de meteorización (Fernández-Jalvo y Andrews 2016: 201205). La meteorización puede afectar a los huesos tanto en la superficie como en el interior del sedimento. En El Espinoso, la disposición en superficie de los restos óseos propició una mayor alteración que se ha valorado en seis grados de meteorización (0-5) siguiendo a Behrensmeyer (1978).

\subsubsection{Disolución}

Este proceso ocurre en la fase diagenética cuando la acción del agua carbonatada de las cuevas sobre el material óseo provoca la pérdida progresiva de la superficie del hueso (Behrensmeyer 1990). La disolución puede ser mecánica a partir del impacto de las partículas sedimentarias abrasivas contenidas en el agua (goteo) o química por la acidez del agua carbonatada (Shipman y Rose 1983, 1988). Esto sucede sobre todo en karst activos por el transporte de elementos químicos solubles en el agua que, al entrar en contacto con los huesos, erosionan su superficie. Además la actividad hídrica puede hacer las funciones de agente acumulador y ser la responsable del desplazamiento y modificación de la posición original de los restos óseos (Behrensmeyer 1982, 1988; Brugal 1994). Para el material de El Espinoso se establecieron cuatro estadios de disolución (Fig. 5A): 'Nula': sin alteración de la coloración, ni de la densidad del hueso; 'Leve': manifestada a través de la pérdida de coloración del hueso en favor de una blanquecina; 'Media': los huesos están más disueltos y gráciles con una 


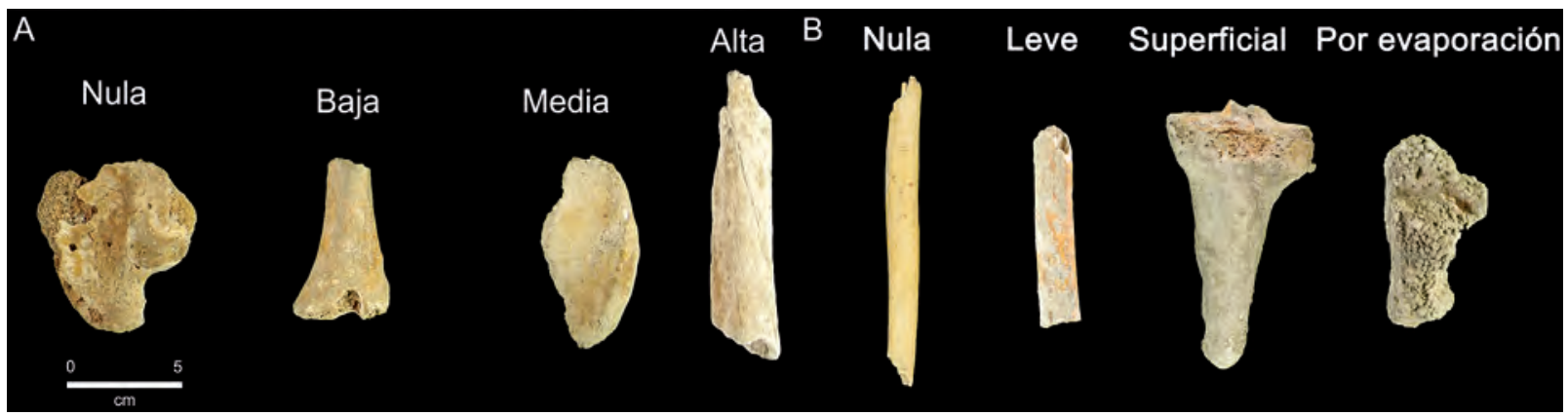

Fig. 5. Grados de disolución (A) y concreción (B) establecidos en los huesos humanos de El Espinoso (en color en la edición electrónica).

coloración más blanca y una densidad ósea menos compacta; 'Alta': la disolución provoca un claro color blanquecino y un riesgo de desintegración serio en los huesos.

\subsubsection{Concreción}

En este proceso diagenético se crea una costra calcítica alrededor del hueso por deslizamiento del agua a través de las fisuras de las rocas, arrastrando con ella todas las sales minerales en disolución que se solidifican sobre los huesos al contacto con el aire de la cavidad. El proceso es parejo o continuista al de la disolución (Fernández López 2000).

Este es un proceso químico muy frecuente en las cavidades calcáreas. El dióxido de carbono atmosférico se disuelve en las aguas superficiales produciendo ácido carbónico que reduce el $\mathrm{pH}$ del agua. Las aguas de escorrentía, que incrementan su acidez con los ácidos húmicos del suelo, entran en contacto con las rocas calizas. Esta interacción produce bicarbonato cálcico, soluble en agua. La evaporación de las gotas de agua que caen al suelo de cueva disminuye la presión del dióxido de carbono y el bicarbonato cálcico que contiene se transforma finalmente en carbonato cálcico (Botella et al. 1999: 182). A partir del tipo de afección que presentaban los huesos se establecieron cuatro estadios de concreción (Fig. 5B): 'Nula': la superficie del hueso está al descubierto sin concreción; 'Leve': la concreción afecta a pequeñas zonas; 'Superficial': la concreción cubre la mayor parte o toda la superficie, la costra es dura, consistente y adherida al hueso; 'Por evaporación': la con- creción es extrema, recubre toda la superficie del hueso, y asciende en pequeños nódulos de costra.

\section{RESULTADOS Y DISCUSIÓN}

\subsection{Tasa de Fragmentación e Índice de Representación Anatómica}

La Tasa de Fragmentación (TF) de todo el depósito arqueológico es de $1,7 \%$, un índice relativamente bajo en comparación con los 1175 restos de taxonomía no identificable, pero presumible pertenencia a Homo sapiens, caracterizados por su pequeño tamaño y alta fragmentación. Además, los huesos humanos con mayor número de restos con identificación anatómica incompleta (vértebras, costillas o falanges) pueden sesgar este resultado, al no haberse empleado para calcular el Número Mínimo de Elementos y la TF. Sin embargo, los huesos densos como el cráneo y los huesos largos ofrecen una tasa suficiente para reconocer la alta fragmentación del depósito. Teniendo en consideración estos factores, este índice sería superior y estaría parcialmente sesgado. La TF (Fig. 6A) varía según la región anatómica. El cráneo, la pelvis y el fémur son los elementos anatómicos más fragmentados del depósito con tasas por encima de 3. Las tasas entre el 2 y el 2,5 de los huesos del brazo (húmero, cúbito, radio) y la tibia y el peroné también son considerables. El resto de elementos anatómicos (tasas en torno a 1), apenas presentan fracturación.

El 16\% del Índice de Representación Anatómica (IRA) del conjunto de la población registrada (20 individuos), indica la pérdida de casi el $85 \%$ 

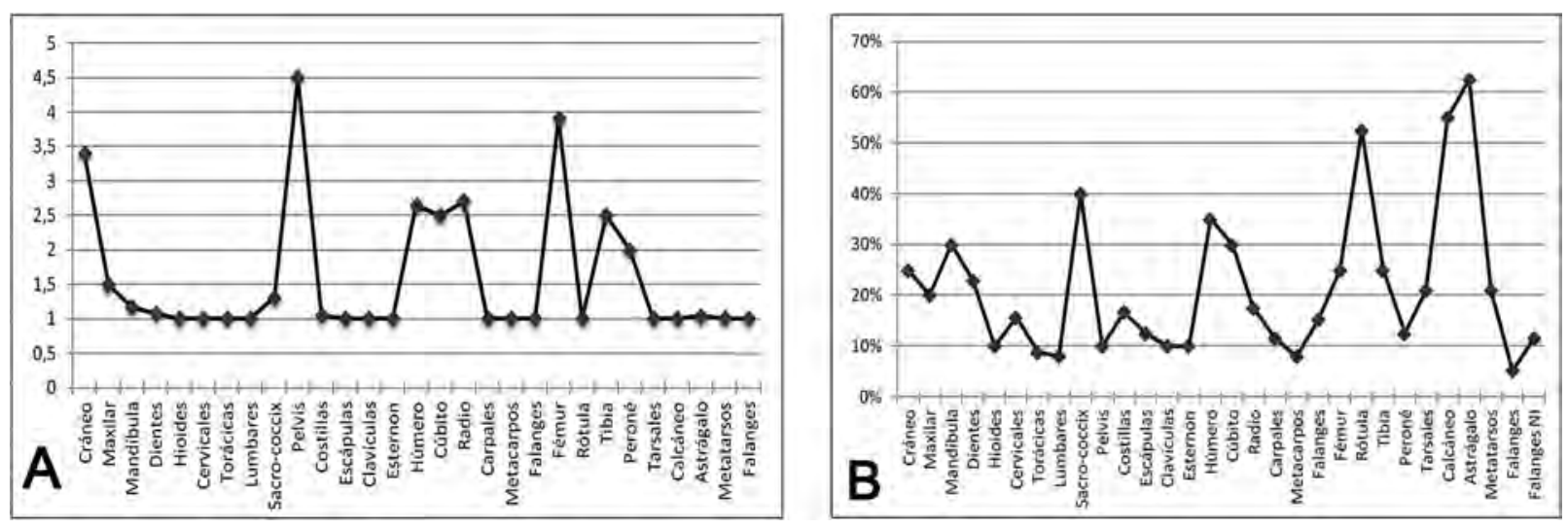

Fig. 6. El Espinoso: A. Tasa de Fragmentación en cada elemento anatómico. B. Índice de Representación Anatómica en cada elemento anatómico. NI: no identificables.

del conjunto original depositado y señala la elevada atrición sufrida en el depósito arqueológico. El IRA también muestra variaciones significativas a nivel anatómico (Fig. 6B) por lo que carece de un único patrón de representación. Predominan los huesos menos densos como la rótula, el calcáneo, el astrágalo o el sacro que superan el 50\% de la muestra. Los huesos largos, el cráneo o los dientes, más compactos, se sitúan entre el 20-30\% en general. El índice de los elementos anatómicos axiales (clavículas, escápulas, costillas, vértebras y pelvis) y las falanges es todavía menor en torno al $10-20 \%$. Hay pues una representación significativa de huesos menos densos, los que suelen escasear en cualquier registro funerario, a costa de los más densos, como los huesos largos y el cráneo, más proclives a una mejor conservación y más llamativos o sugerentes para ser transportados y darles un segundo enterramiento.

Los datos ofrecidos por la TF y el IRA descartan que los fenómenos de conservación diferencial (Henderson 1987; Stodder 2008) sean los responsables de esta representación esquelética. El hecho de que falte un único patrón de conservación y fragmentación sugiere una alteración antrópica del depósito sepulcral. Los restos óseos se recuperaron esparcidos por toda la superficie del suelo de la cueva y sin aparente conexión anatómica pero nos encontramos ante un enterramiento primario múltiple caracterizado por inhumaciones primarias sucesivas. La preponderancia ya comentada de huesos de menor tamaño y densidad sobre los huesos largos y el cráneo (que a su vez son los más fracturados) indica una serie inicial de ente- rramientos primarios sucesivos. Después se pudo remover los restos limpiando el espacio sepulcral para dar cabida a nuevos deposiciones bien con la reagrupación de huesos, o hipotéticamente, con la extracción de los más representativos del esqueleto humano para darles una nueva inhumación en el exterior de la cueva.

\subsection{Resultados tafonómicos}

\subsubsection{Fracturación}

La colección ósea de El Espinoso tiene un $85,2 \%$ de NR afectados por fracturación, erosión y pérdida del tejido óseo. En particular, todos los huesos largos presentan fracturas en seco (Fig. 7): post-mortem recientes $(61,4 \%)$, seguidas por las post-mortem antiguas $(38,6 \%)^{8}$. Falta la fracturación en fresco, característica de actividades carniceras humanas. La fracturación post-mortem reciente puede producirse por alteración antrópica moderna, o durante el proceso de recogida, traslado y almacenamiento de los materiales. Finalmente, la fracturación post-mortem antigua se relaciona con agentes naturales físico-químicos. Predomina con gran diferencia el ángulo de fractura oblicuo $(76,8 \%)$, seguido del mixto $(16,4 \%)$ y

\footnotetext{
${ }^{8}$ La fracturación post-mortem 'antigua' corresponde a la producida tras la bioestratinomía de los restos. Difiere de la 'reciente' porque el paño de fractura ha sido concrecionado en algún momento del pasado.
} 
recto $(6,8 \%)$. Destaca el tipo transversal de perfil de la fractura, relacionado con una fracturación causada por agentes físico-químicos $(98 \%)$, sobre el curvado (2\%), más propio de fracturaciones en fresco (Sala et al. 2015: 118). El borde irregular $(92,1 \%)$, relacionado con fracturas en seco, supera mayoritariamente al borde suave $(7,9 \%)$, propio de fracturaciones antrópicas carniceras en fresco (Vila y Mahieu 1991: 40). Por último, la circunferencia de la fractura de los huesos largos continúa la tónica dominante en el análisis. Un $66,2 \%$ muestra la circunferencia completa, característica de las fracturaciones en seco (Vila y Mahieu 1991: 41). Le siguen con un 1\% (3/4 de circunferencia), $28,3 \%$ (1/2 de circunferencia) y $4,4 \%$ ( $1 / 4$ de circunferencia).

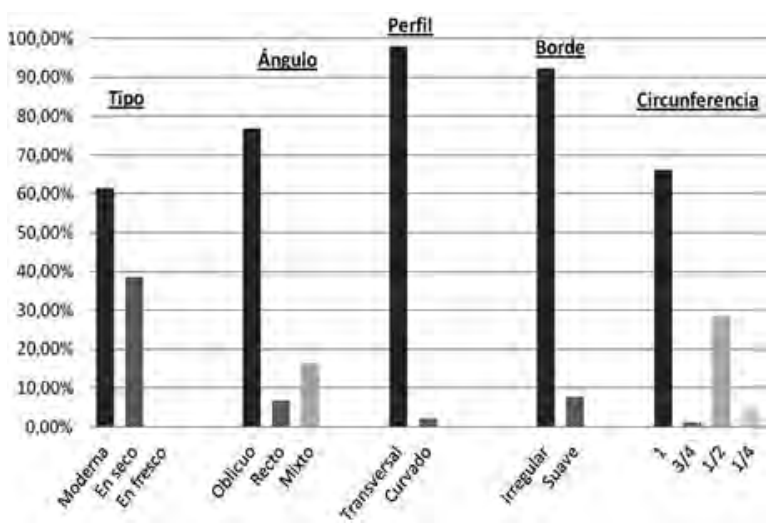

Fig. 7. El Espinoso: análisis de la fracturación de los huesos largos.

Los resultados del análisis de la fracturación de los huesos largos de El Espinoso descartan cualquier manipulación antrópica relacionada con fenómenos de canibalismo, ya sea ritual o alimenticio, y demuestran que los agentes naturales físico-químicos y la alteración moderna del yacimiento son los responsables de este perfil de fracturación. La total ausencia de marcas de corte en los huesos humanos corrobora estos resultados. No obstante, el $12 \%$ de los 33 restos de fauna hallados junto a los restos humanos tiene marcas de corte y el $15 \%$ está fracturado en fresco. Se desconoce si estos restos forman parte o no de algún tipo de ajuar u ofrenda funeraria. Nuevas dataciones podrán aclarar la contemporaneidad de ambos conjuntos fósiles.

\subsubsection{Termoalteraciones}

La proporción de termoalteraciones (variaciones de coloración) en el registro óseo del yacimiento es del 3,3\% del NR. No llegan al 1\% de la colección las coloraciones marrón y negra $(0,2 \%$ y $0,5 \%$ respectivamente). No obstante, y a pesar de su baja intensidad $(2,6 \%$ de los huesos), resulta llamativa la termoalteración definida como quemado por contacto con carbones o sedimentos quemados. Este tipo de marcas aparece en 6 metatarsos, 4 cúbitos y 3 tibias, entre otros restos humanos distribuidos a lo largo del Sector $\mathrm{B}$, y se hallaron carbones en sus zonas de procedencia. Dos evidencias relacionan esta alteración tafonómica bien con un leve contacto directo del hueso con fuentes de calor o bien con carbones o sedimentos quemados que impregnarían el hueso posteriormente. La primera es la localización de las huellas observadas en pequeñas zonas de cada resto óseo. La segunda es la coloración negra generalizada en los escasos restos afectados por quemado, la cual sugiere unas temperaturas entre $300-350^{\circ} \mathrm{C}$ según los esquemas establecidos para las variaciones de coloración por Etxeberría (1994) y Fernández-Crespo (2016). Como todas estas termoalteraciones se han producido "en seco" parece seguro que ocurrieron tras el depósito, una vez destruidas las partes blandas y paquetes musculares del cuerpo humano. Con los datos ofrecidos sería aventurado afirmar que las termoalteraciones resultaran de algún ritual de inhumación relacionado con el encendido de hogares. Sería más coherente conectarlas con iluminación utilizada durante la deposición de nuevos cadáveres o con la hipotética extracción de los cráneos y huesos largos de la cueva. Es conocido el uso del fuego como iluminación o como estrategia profiláctica en cavidades con contextos funerarios (Lomba et al. 2009), pero sin dataciones ni estudios antracológicos de los carbones queda abierta su contemporaneidad o posterioridad al uso sepulcral de la cavidad.

\subsubsection{Marcas de carnívoros}

Lo relevante es la escasez de estas huellas (punciones $0,3 \%$; mordisqueo $0,4 \%$; arrastres $0,2 \%$ ), ninguna de las cuales llega al $1 \%$ del 
total de 12 huesos humanos afectados. Pertenecen a cinco individuos diferentes. Los elementos anatómicos varían desde huesos poco densos como el astrágalo, hasta huesos largos como el radio o la tibia, y varios fragmentos de pelvis y cráneo. Estos datos llaman la atención por su debilidad estadística en el total de la muestra estudiada, considerando que los materiales estaban en superficie. No obstante, podría explicarse por el acceso un tanto dificultoso a la cueva y por la ausencia de restos óseos de carnívoros en la misma. Esta baja frecuencia también se puede deber al mal estado de conservación de los huesos debido a otros procesos naturales (disolución, concreción) que erosionaron o recubrieron la superficie ósea.

\subsubsection{Pisoteo}

El mínimo pisoteo $(0,7 \%)$ identificado en el conjunto osteológico de El Espinoso puede deberse a las razones antes expuestas: difícil acceso a la cavidad o mala conservación de los restos. La elección de cuevas inaccesibles por los grupos humanos de la Edad del Bronce para dar sepultura a sus congéneres es algo atestiguado y puede suponer una barrera a animales o personas. No obstante, la alta fragmentación de los restos puede relacionarse con las visitas contemporáneas a la cueva. A veces, resulta difícil reconocer el pisoteo, pues otros agentes modificadores físicoquímicos también pueden estar detrás de estas fracturas. Sin embargo, debe tenerse en cuenta en yacimientos donde el registro arqueológico está en superficie.

\subsubsection{Meteorización}

La distribución de los diferentes grados de meteorización en los restos humanos de El Espinoso permite discutir el origen de la acumulación ósea. Un estadio preponderante en todos los huesos podría atribuirse a un episodio de tipo catastrófico, resultado de un mismo y rápido evento. Es decir, el conjunto de las inhumaciones sería sincrónico. Por lo contrario, una distribución mucho más heterogénea y diversa en grados de meteorización de la colección ósea apuntaría a un fenómeno diacrónico, es decir, a una acumulación paulatina de los huesos durante años. Además habría que conocer los factores que pueden distorsionar la conservación y por tanto la interpretación de la colección. Las circunstancias del enterramiento y las condiciones atmosféricas del lugar de deposición de los cadáveres pueden inhibir la presencia de otros estadios. A la vez la existencia de diferentes microambientes en el yacimiento, generadores de variabilidad microclimática, pueden provocar procesos tafonómicos de diversa intensidad (Behrensmeyer 1978).

En El Espinoso se descarta la hipótesis de un único episodio de acumulación de los restos humanos, pues muestran todos los grados de meteorización y tres de ellos están bien representados (Fig. 8). Como todos los huesos estaban a la intemperie, su alteración fue más importante que si hubieran estado bajo tierra. No obstante, su depósito en una sala pequeña y difícilmente accesible de la cueva actuó como aislante frente los procesos que a menudo causan un mayor grado de meteorización (lluvia, sol, etc.). En cambio, la humedad y la precipitación de agua con carbonato cálcico de manera constante en la cueva sí propició cierto grado de meteorización. A la vista de los datos sobre los distintos grados de meteorización del yacimiento de El Espinoso, se propone una acumulación paulatina del depósito durante un período que podría abarcar varias décadas. La datación absoluta de todos los individuos permitirá conocer con exactitud la dispersión cronológica del fenómeno funerario.

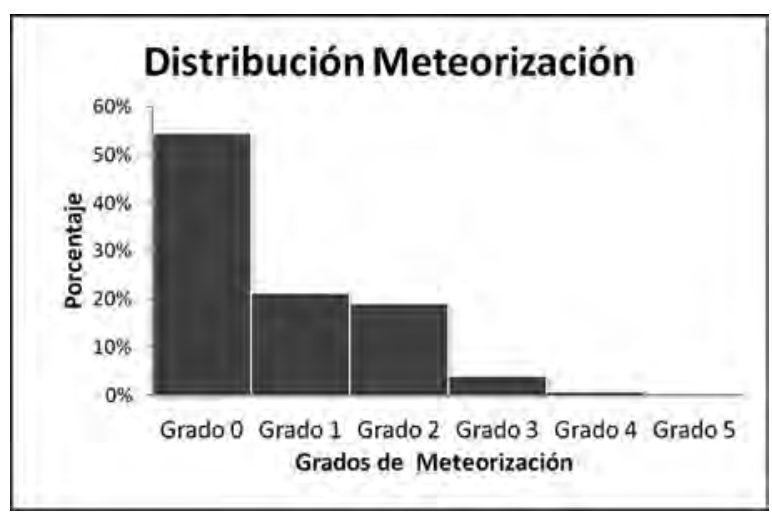

Fig. 8. El Espinoso: distribución porcentual del Número de Restos que representa cada estadio de meteorización. 


\subsubsection{Disolución}

El 95\% del NR de la colección está afectada por la disolución (Fig. 9A), un proceso muy habitual en ambientes kársticos, donde la humedad es alta y el carbonato cálcico está muy presente. La precipitación de agua con carbonato cálcico sobre los huesos produce una fuerte deshidratación que erosiona de modo paulatino la superficie del hueso, volviéndole frágil y deleznable, con tintes blanquecinos. Este proceso ha afectado con diferente intensidad a los materiales con ejemplos de disolución baja $(19,5 \%)$, media $(32,1 \%)$ y alta $(44,2 \%)$. Este esquema encaja perfectamente con el modelo de la meteorización y permite descartar por completo que un único episodio de inhumación fuese el causante de la acumulación de los restos.

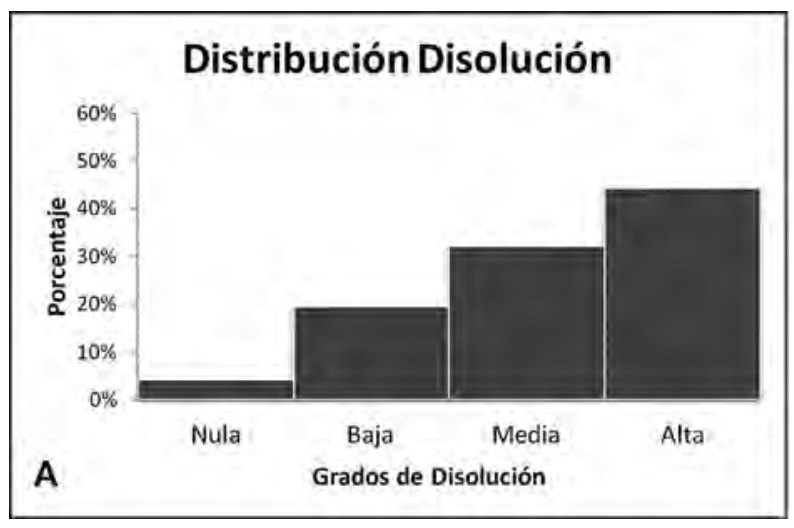

Fig. 9. El Espinoso: distribución porcentual del Número de Restos que representa cada estadio de disolución (A) y concreción (B).

\subsubsection{Concreción}

El 70\% del NR se ha visto afectado por fenómenos de concreción (Fig. 9B), cuyas variantes dependen del tipo de contacto del agua con los huesos. El carbonato cálcico, impregnado en el sedimento o disuelto en el agua propició una concreción leve $(26,8 \%)$. Por otra parte, el agua que caía directamente sobre la superficie del hueso creó un tipo de concreción superficial $(35,4 \%)$ en capas finas. Finalmente, donde había un goteo continuo del agua sobre los huesos, se iba formando una costra más gruesa, transformada en concreción por evaporación $(7,6 \%)$. La concreción corrobora, pues, los resultados obtenidos

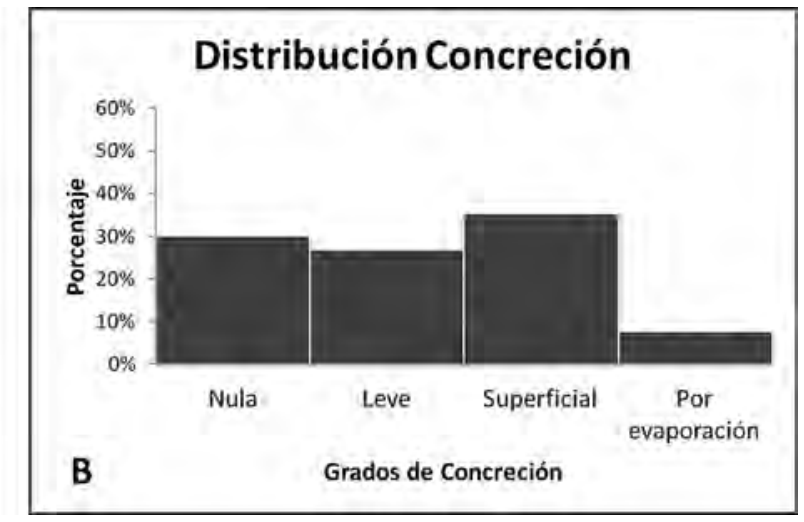

por la meteorización y la disolución, aunque es necesario considerar la distribución espacial de los diferentes estadios de afección de cada alteración tafonómica para conseguir una visión homogeneizadora del proceso.

\subsection{Análisis espacial}

Los huesos humanos estudiados se agrupan en los recovecos y paredes de los márgenes de la Sala de los Muertos. En su centro (único espacio lo bastante alto y ancho para estar erguido) los restos humanos son una excepción. Más que en una conservación diferencial, resulta coherente pensar que fuera un área de tránsito y frecuentación durante el uso funerario de la sala. De los Sectores A y B proceden el $22,2 \%$ y $42,3 \%$ de los huesos respectivamente. Finalmente, los huesos del Sector C representan el 32,2\% del total pero, en proporción, son de menor tamaño y hay menos identificables. Como posibles causas de desplazamiento de los restos hacia las paredes se plantean las siguientes situaciones:

a) El grupo o grupos humanos que inhumaban allí a sus muertos aprovechaban los recovecos naturales de la cueva para dar cobijo a los distintos individuos. Estos "nichos" actuarían a modo de tumbas, dando un espacio de protección a los restos de los difuntos. 
b) En las continuas deposiciones a lo largo del tiempo se fueron desplazando o reagrupando los restos óseos de los individuos allí depositados hacia las paredes de la cavidad para dar cabida a otros nuevos, incluso extrayendo algunos de la cueva.

c) La percolación del agua sobre los huesos pudo propiciar en momentos de lluvias ex- tremas la remoción de alguno que quedarían atrapados en los recovecos de menores dimensiones de la sala mortuoria.

d) Las visitas modernas a la cueva influyeron aún más en la dispersión de los huesos hacia los márgenes de la cavidad, dejando un "pasillo transitable" en los espacios centrales de ambos Sectores.
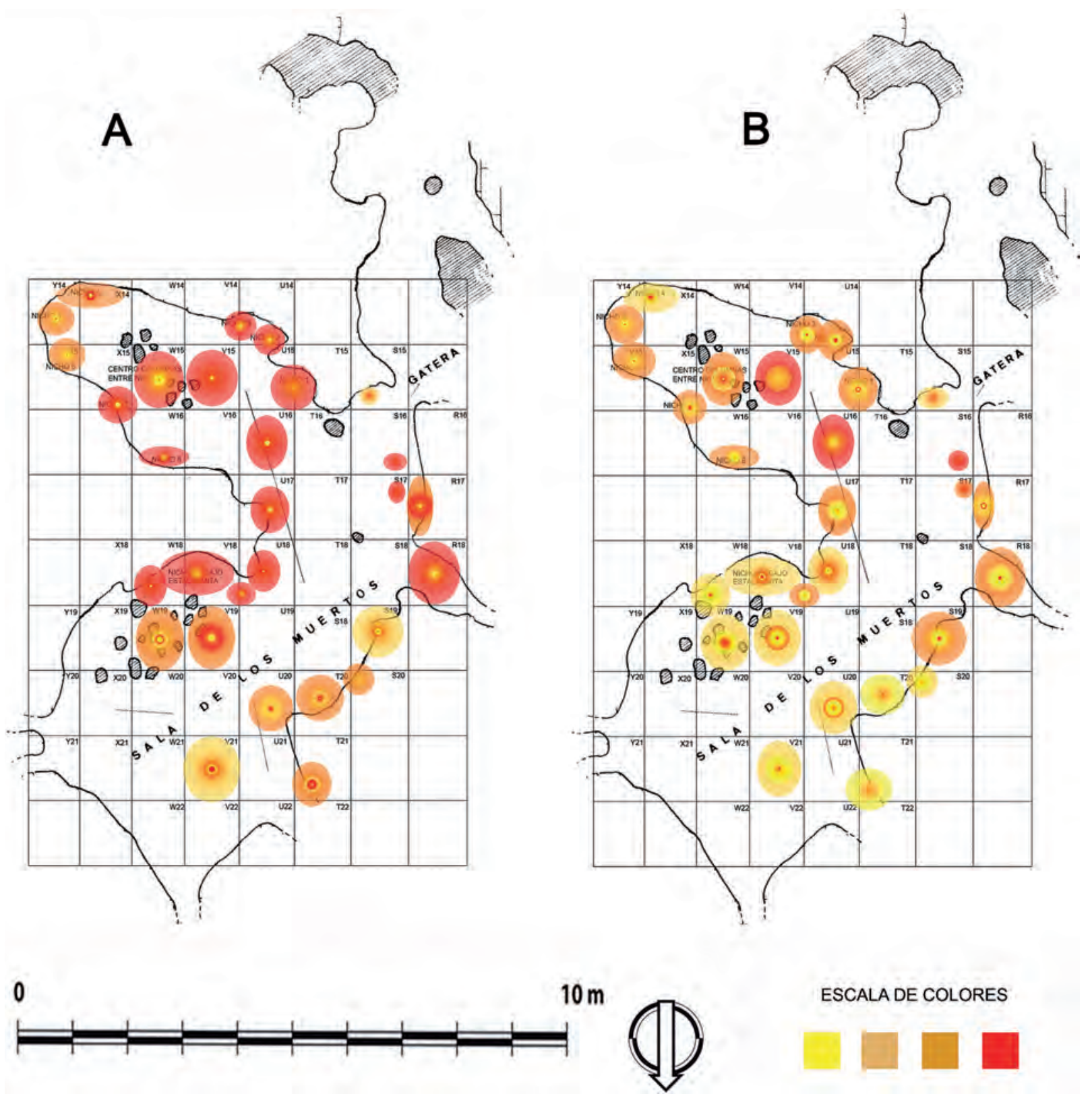

ESCALA DE COLORES

Fig. 10. Distribución espacial del Número de Restos por cada grado de disolución (A) y concreción (B): amarillo nula/nula; mostaza baja/leve; naranja media/superficial; rojo alta/por evaporación (en color en la edición electrónica). 
Desde un primer momento se pensó en la posibilidad de una afectación diferencial de los procesos tafonómicos diagenéticos en función de su localización espacial. Dicha posibilidad se evaluó mediante un análisis espacial de la distribución (en NR) de cada estadio de disolución y concreción por cuadro de excavación (Fig. 10). En el Sector A predomina la disolución alta y hay concreción superficial y por evaporación (tonos rojizos y naranjas) por lo que los huesos están mas alterados que en los Sectores B y C. En el Sector B la disolución es media baja y no hay concreción (tonos mostazas y amarillos). Así pues, el Sector A sería el más proclive a haber tenido mayor contacto con el agua. En resumen, los Sectores A y B con los hallazgos más importantes en términos cuantitativos y cualitativos se solapan en cierta medida con las dos zonas tafonómicas definidas en función de los grados de disolución y concreción observados. El Sector $\mathrm{C}$, el siguiente en restos óseos, tiende a tipos de disolución y concreción más cercanos a los del Sector B. Estas divergencias en el impacto de los procesos tafonómicos explican la variabilidad en la conservación de los restos.

\section{CONCLUSIONES}

Este trabajo es pionero en varios sentidos. Estudia El Espinoso, el único enterramiento múltiple de la Edad del Bronce conocido hasta el momento en Asturias (cf. Sección 2), y lo hace de manera exhaustiva desde un enfoque tafonómico. Este enfoque se propone como marco metodológico para el estudio de cuevas sepulcrales con inhumaciones depositadas en superficie, ya que la Tafonomía toma en consideración el conjunto de procesos naturales y antrópicos, bioestratinómicos y diagenéticos, que alteran los depósitos arqueológicos funerarios. Se resumen a continuación las conclusiones e interpretaciones aportadas:

1. El acceso difícil a la cavidad de El Espinoso y la elección habitual por parte de los grupos humanos de la Edad del Bronce de lugares aislados para proteger a los inhumados del exterior sugiere el uso de andamiajes o escalas para subir los cadáveres a la cueva. Una vez allí, el paso a la Sala de los Muertos debió requerir algún mecanismo de arrastre pues la galería de tránsito va reduciendo sus dimensiones hasta el punto de tener que reptar para llegar a dicha sala. Las pocas marcas de pisoteo y de carnívoros son ejemplos de esta inaccesibilidad.

2. El predominio de huesos de menor tamaño y densidad que los habituales en enterramientos secundarios en la representación esquelética indica que se trata de un enterramiento primario de carácter múltiple. Las inhumaciones primarias se fueron sucediendo durante un periodo de tiempo prolongado, dados los heterogéneos grados de meteorización de los huesos. Nuevas dataciones de diversos individuos ayudarán a confirmar o refutar la sincronía o diacronía del evento.

3. El tipo de termoalteraciones observadas en algunos huesos señala su posterioridad al depósito $\mathrm{y}$, por tanto, su posible relación con la iluminación empleada cuando volvía a utilizarse el espacio sepulcral, descartando a priori que formase parte del ritual de inhumación. La ausencia de marcas de corte en los huesos excluye cualquier tipo de fenómeno de canibalismo o descarnado de los cadáveres.

4. Los datos extraídos de la TF y del IRA respecto al tipo de huesos más representados y más fracturados explican la escasez o ausencia de los restos más densos. Estos resultados sugieren que los cráneos y huesos largos eran extraídos de la cueva para darles un segundo enterramiento.

5. El análisis de las fracturas de los huesos denota su posterioridad al momento del depósito y los conecta con procesos diagenéticos físicoquímicos (fracturas post-mortem antiguas) y con la alteración humana reciente del yacimiento (fracturas post-mortem recientes).

6. El análisis espacial de la disolución y la concreción en los huesos revela que estas alteraciones tafonómicas, originadas por las diferentes condiciones ambientales existentes en cada zona, tienen un impacto diferencial sobre el depósito.

7. Las catas y remociones realizadas por buscadores de tesoros, la extracción de los elementos de adorno del ajuar funerario y la alta fracturación post-mortem reciente de los huesos prueban la alteración antrópica contemporánea del yacimiento y advierten de las escasas medidas de protección y conservación con las que cuenta.

8. El exhaustivo estudio tafonómico efectuado ha permitido reconstruir la historia tafonómica de la acumulación ósea. Los individuos eran sepultados al abrigo de la cavidad en un lapso de tiempo prolongado. Para ello se valían de los

Trab. Prehist., 74, N. ${ }^{\circ}$ 2, julio-diciembre 2017, pp. 278-295, ISSN: 0082-5638

doi: $10.3989 /$ tp.2017.12195 
diferentes recovecos y nichos naturales de la cueva, redistribuyendo el espacio sepulcral si nuevas inhumaciones lo hacían necesario. Más tarde, las alteraciones naturales y antrópicas del yacimiento fueron removiendo el material hasta dejarlo en la posición actual.

Finalmente, El Espinoso se añade a otras cuevas sepulcrales con depósitos en superficie conocidos en el Oriente de Asturias como El Toral III, El Bufón, La Llana y Fuentenegroso. Las cronologías de estos yacimientos abarcan desde el Neolítico Final/Calcolítico Inicial hasta el Bronce Final/Hierro Inicial, lo que plantea la posible existencia de una tradición funeraria en esta región durante al menos dos milenios.

\section{AGRADECIMIENTOS}

Este artículo arranca del Trabajo Fin de Máster del primero de los autores, elaborado en la Universidad de Cantabria y en el Instituto Internacional de Investigaciones Prehistóricas de Cantabria (IIIPC). En especial, se agradece la consulta de la colección de referencia de su Laboratorio de Bioarqueología. Eduardo Palacio realizó las imágenes en el propio yacimiento. Nuestro reconocimiento también al Laboratorio de Evolución Humana de la Universidad de Burgos y al Dr. J. M. Carretero, que de manera desinteresada permitió una estancia de investigación en dicho centro muy útil para la ejecución del trabajo.

\section{BIBLIOGRAFÍA}

Andrews, P. y Fernández Jalvo, Y. 1997: "Surface modifications of the Sima de los Huesos fossil humans". Journal of Human Evolution 33: 191-217.

Andrews, P. y Whybrow, P. 2005: “Taphonomic observations on a camel skeleton in a desert environment in Abu Dhabi". Palaeontologia Electronica 8(1): 1-17.

Arias Cabal, P. y Armendáriz, A. 1998: “Aproximación a la Edad del Bronce en la Región Cantábrica”. En R. Fábregas (ed.): A Idade do Bronce en Galicia: novas perspectivas. Cadernos do Seminario de Sargadelos 77: 47-80.

Arias Cabal, P.; Martínez Villa, A. y Pérez Suárez, C. 1986: "La cueva sepulcral de Trespando (Corao, Cangas de Onís, Asturias)". Boletín del Instituto de Estudios Asturianos 120: 1259-1289.
Armendáriz, A. 1990: "Las cuevas sepulcrales en el País Vasco". Munibe 42: 153-160.

Armendáriz, A. y Etxeberría, F. 1983: "Las cuevas sepulcrales de la Edad del Bronce en Guipúzcoa". Munibe 35: 247-354.

Armentano i Oller, N.; Gràcia, X. E.; Nociarová, D. y Morera, A. M. 2012: "Taphonomical study of the anthropological remains from Cova Des Pas (Minorca)". Quaternary international 275: 112-119.

Armentano i Oller, N. 2014: La reconstrucció tafonòmica dels enterraments col-lectius. Tesis i dissertacions electròniques, Universitat Autònoma de Barcelona [Bellaterra].

Barroso, R.; Bueno, P.; Camino, J. y Balbín, R. de 2007: "Fuentenegroso (Asturias), un enterramiento del Bronce Final-Hierro en el marco de las comunidades atlánticas peninsulares". Pyrenae 38, 2: 7-32.

Behrensmeyer, A. 1978: "Taphonomic and ecological information from bone weathering". Paleobiology 4 (2): 150-162.

Behrensmeyer, A. 1982: "Time resolution in fluvial vertebrate assemblages". Paleobiology 8: 221-227.

Behrensmeyer, A. 1988: "Vertebrate preservation y fluvial channels". Palaeogeography, Palaeoclimatology, Palaeoecology 63: 183-199.

Behrensmeyer, A. 1990: "Bones". En E. D. Briggs y P. R. Crowther (eds.): Paleobiology. A synthesis. Blackwell Scientific. Oxford: 232-235.

Bello, S. y Andrews, P. 2006: "The intrinsic pattern of preservation of human skeletal and its influence on interpretation of funerary behaviors". En R. Gowland y C. Knusel (eds.): Social archaeology of funerary remains. Oxbow Books. Oxford: 1-13.

Binford, L. 1981: Bones, Ancient Men and Modern Myths. Studies in archaeology, Academic Press. Orlando.

Blas Cortina, M. A. de 1983: La prehistoria reciente en Asturias. Estudios de Arqueología Asturiana 1, Fundación Pública de Cuevas y Yacimientos Prehistóricos de Asturias. Oviedo.

Blas Cortina, M. A. de 2011: "Minería prehistórica del cobre en el reborde septentrional de los Picos de Europa: las olvidadas labores de 'El Milagro' (Onís, Asturias)". Veleia 24-25: 723-753.

Blas Cortina, M. A. de 2014: "El laboreo del cobre en la Sierra del Aramo (Asturias) como referente cardinal de la minería prehistórica de la Región Cantábrica". Cuadernos de Prehistoria y Arqueología de la Universidad de Granada 24: 45-84.

Botella, M.; Alemán, I. y Jiménez, S. 1999: Los huesos humanos: manipulación y alteraciones. Bellaterra, Barcelona.

Brugal, J. P. 1994: "Introduction générale: action de l'eau sur les ossements et les assemblages fossils". En Outillage peu élaboré en os et en bois de Cervidés IV, Table Ronde Taphonomie - Bone Modification (Paris 1991). Artefacts 9: 121-129. 
Cuenca Solana, D. 2013: Utilización de instrumentos de concha para la realización de actividades productivas en las formaciones económico-sociales de cazadores-recolectores-pescadores y primeras sociedades tribales de la fachada atlántica europea. PuBLiCan, Ediciones Universidad de Cantabria. Santander.

Davidson, I. y Estévez, J. 1986: "Problemas de Arqueotafonomía. Formación de yacimientos con fauna". Quaderns I: 67-84.

Domínguez-Rodrigo, M.; Juana, S. de; Galán, A. B. y Rodríguez, M. 2009: "A new protocol to differentiate trampling marks from butchery cut marks". Journal of Archaeological Science 36: 2643-2654.

Efremov, I. A. 1940: "Taphonomy: a new branch of Paleontology". Pan-American Geologist 74: 81-93.

Esparza Arroyo, A.; Velasco Vázquez, J. y Delibes de Castro, G. 2012: "Exposición de cadáveres en el yacimiento de Tordillos (Aldeaseca de la Frontera, Salamanca). Perspectiva bioarqueológica y posibles implicaciones para el estudio del ritual funerario de Cogotas I". Zephyrus LXIX: 95-128.

Etxeberría, F. 1994: “Aspectos macroscópicos del hueso sometido al fuego. Revisión de las cremaciones descritas en el País Vasco desde la Arqueología”. Munibe 46: 111-116.

Fernández-Crespo, T. 2016: "El papel del fuego en los enterramientos neolíticos finales/calcolíticos iniciales de los abrigos de la Sierra de Cantabria (valle medio-alto del Ebro)". Trabajos de Prehistoria 73 (1): 128-146.

Fernández-Jalvo, Y. y Andrews, P. 2016: Atlas of Taphonomic Identifications. Springer. London.

Fernández López, S. R. 2000: Temas de Tafonomía. Departamento de Paleontología. Universidad Complutense de Madrid. http://pendientedemigracion. ucm.es/centros/cont/descargas/documento 11157. $\operatorname{pdf}(4 / \mathrm{XII} / 2015)$

Gaudzinski-Windheuser, S.; Kindler, L.; Rabinovich, R. y Goren-Inbar, N. 2010: "Testing hetereogeneity in faunal assemblages from archaeological sites. Tumbling and trampling experiments at the EarlyMiddle Pleistocene site of Gesher Benot Ya'aqov (Israel)". Journal of Archaeological Science 37: 3170-3190.

González Morales, M. R. 1995: "Memoria de los trabajos de limpieza y toma de muestras en los yacimientos de las cuevas de Mazaculos y El Espinoso (La Franca, Ribadedeva) y La Llana (Andrín, Llanes) en 1993". Excavaciones Arqueológicas en Asturias 1991-94: 65-78.

Henderson, J. 1987: "Factors determining the state of preservation of human remains". En A. Boddington, A. Garland y R. Janaway (eds.): Death, decay and reconstruction. Approaches to archaeology and forensic science. Manchester University Press. Manchester: 43-54.

Hierro Gárate, J. A. 2011: "La utilización sepulcral de las cuevas en Época Visigoda: los casos de Las
Penas, La Garma y El Portillo del Arenal (Cantabria)". Munibe 62: 351-402.

Lomba, J.; López Martínez, M. V. y Ramos Martínez, F. 2009: "Un excepcional sepulcro del Calcolítico: Camino del Molino (Caravaca de la Cruz)". XX Jornadas de Patrimonio Cultural de la Región de Murcia (Cartagena, Cieza, Águilas, Puerto Lumbreras, Murcia 2009): 205-219. Murcia.

Lull, V.; Micó, R.; Rihuete, C. y Risch, R. 1999: La Cova des Càrritx y la Cova des Mussol. Ideología y sociedad en la prehistoria de Menorca. Consell Insular de Menorca, Ajuntament de Ciutadella, Fundació Rubio. Barcelona.

Lyman, R. L. 1994a: "Quantitative Units and Terminology in Zooarchaeology". American Antiquity 59, 1: 36-71.

Lyman, R. L. 1994b: Vertebrate taphonomy. Cambridge manuals in archaeology, Cambridge University Press. Cambridge.

Lyman, R. L. y Fox, G. L. 1989: “A critical evaluation of bone weathering as an indication of bone assemblage formation". Journal of Archaeological Science 16: 293-317.

Marín-Arroyo, A. B. 2010: Arqueología en el cantábrico oriental durante la transición Pleistoceno/Holoceno. La Cueva del Mirón. PUbliCan, Ediciones Universidad de Cantabria. Santander.

Marín-Arroyo, A. B. 2015: "Taphonomic study of human remains from the Magdalenian burial in El Mirón Cave (Cantabria, Spain)". Journal of Achaeological Science 60: 57-65.

Mateos, A. 2003: "Estudio de la fragmentación de falanges y mandíbulas en la secuencia temporal del 19000-13000 BP de la Cueva de Las Caldas (Priorio, Oviedo). Implicaciones paleoeconómicas: nutrición y subsistencia”. Gallaecia 22: 9-20.

Müller, A. H. 1951: "Grundlagen der Biostratonomie". Deutsche Akademie der Wissenschaften zu Berlin, 1-147.

Müller, A. H. 1963: "Lehrbuch der Paläozoologie". 1. Allgemeine Grundlagen. C. Die Fossilisationslehre. Fischer. Jena: 17-134.

Noval Fonseca, M. A. 2014: "Excavación arqueológica en la cueva de El Toral III (Andrín, Llanes)". Excavaciones Arqueológicas en Asturias 2007-2012. En el centenario del descubrimiento de la caverna de la Peña de Candamo. Gobierno del Principado de Asturias. Oviedo: 381-384.

Olsen, S. L. y Shipman, P. 1988: "Surface modification on bone: trampling versus butchery". Journal of Archaeological Science 15: 535-553.

Ontañón, R. 2003: Caminos hacia la complejidad: el Calcolítico en la región cantábrica. Universidad de Cantabria. Santander.

Pérez Ripoll, M. 1992: Marcas de carnicería, fracturas intencionadas y mordeduras de carnívoros en huesos prehistóricos del Mediterráneo español. Colección 
Patrimonio 15, Instituto de Cultura "Juan Gil-Albert”, Diputación Provincial de Alicante. Alicante.

Quesada, J. M. 2003: Modelos de asentamiento y estrategias de subsistencia en el Paleolítico Superior Cantábrico. Tesis doctoral leída en 1997. Universidad Complutense de Madrid http://eprints.ucm.es/ tesis/19972000/H/0/H0049501.pdf

Reimer, P. J.; Bard, E.; Bayliss, A.; Beck, J. W.; Blackwell, P. G.; Ramsey, C. B.; Buck, C. E.; Cheng, H.; Edwards, R. L.; Friedrich, M.; Grootes, P. M.; Guilderson, T. P; Haflidason, H.; Hajdas, I.; Hatté, C.; Heaton, T. J.; Hoffmann, D. L.; Hogg, A. G.; Hughen, K. A.; Kaiser, K. F.; Kromer, B.; Manning, S. W.; Niu, M.; Reimer, R. M.; Richards, D. A.; Scott, E. M.; Southon, J. R.; Staff, R. A.; Turney, C. S. M.; van der Plicht, J. 2013: "IntCal13 and Marine13 radiocarbon age calibration curves $0-50,000$ years cal BP". Radiocarbon 55(4): 1869-1887.

Reverte, J. M. 1991: Antropología forense. Ministerio de Justicia, Secretaria General Técnica. Centro de Publicaciones. Madrid.

Sala, N. 2012: Tafonomía de yacimientos kársticos de carnívoros en el Pleistoceno. Tesis Doctoral. Universidad Complutense de Madrid. http://eprints.sim. ucm.es/16240/ (25/II/2014)

Sala, N.; Arsuaga, J. L.; Martínez, I. y Gracia-Téllez, A. 2015: "Breakage patterns in Sima de los Huesos (Atapuerca, Spain) hominin sample". Journal of Archaeological Science 55: 113-121.

Shipman, P. y Rose, J. 1983: "Evidence of butchery and hominid activities at Torralba and Ambrona: an evaluation using microscopic techniques". Journal of Archaeological Science 10: 465-474.

Shipman, P. y Rose, J. 1988: "Bone tools: an experimental approach". En S. L. Olsen (ed.): Scanning Electron Microscopy in Archaeology. British Archaeological Reports International Series 452, Archaeopress. Oxford: 303-335.

Solari Giachino, A. 2010: Identificación de huellas de manipulación intencional en restos óseos humanos de origen arqueológico. Tesis Doctoral. Universidad de Granada. http://hdl.handle.net/10481/15067 (3-IV-2014)
Soler Díaz, J. A. y Roca de Togores, C. 2012: "Ritual funerario en la Cova d'En Pardo ca. 3.350-2.850 CAL ANE: espacialidad, cronología y territorio cultural". En J. A. Soler (ed.): Cova d'En Pardo: arqueología en la memoria: excavaciones de $M$. Tarradell, V. Pascual y E. Llobregat (1961-1965), catálogo de materiales del Museo de Alcoy y estudios a partir de las campañas del MARQ (19932007) en la cavidad de Planes, Alicante. Fundación MARQ. Alicante: 205-2048.

Soler Díaz, J. A.; Roca de Togores, C.; Esquembre, M. A.; Gómez, O.; Boronat, J. D.; Benito, M.; Ferrer, C. y Bolufer, J. 2016: "Progresos en la investigación del fenómeno de inhumación múltiple en La Marina Alta (Alicante). A propósito de los trabajos desarrollados en la Cova del Randero de Pedreguer y en la Cova del Barranc del Migdia de Xàbia”. Del neolític a l'edat del bronze en el Mediterrani occidental. Estudis en homenatge a Bernat Martí Oliver. Trabajos Varios del S.I.P. 119, Diputación de Valencia. Valencia: 323-348.

Stodder, A. 2008: "Taphonomy and the nature of archaeological assemblages". En M. Katzenberg y S. Saunders (eds.): Biological anthropology of human skeletons. John Willey \& Sons. Hoboken-New Jersey: 71-114.

Valle, M. Á.; Serna, A.; Muñoz, E. y Morlote Expósito, J. M. 1996: "Las cuevas sepulcrales de la Edad del Hierro en Cantabria". La arqueología de los cántabros. Actas de la I Reunión sobre la Edad del Hierro en Cantabria (Santander 1995): 195-279. Santander.

Vila, P. y Mahieu, E. 1991: "Breakage patterns of human long bones". Journal of Human Evolution 21: 27-48.

Weigelt, J. 1927: “Ubre Biostratonomie”. Der Geologe 42: 1069-1076.

Yravedra Sainz de los Terreros, J. 2001: Zooarqueología de la Península Ibérica: implicaciones tafonómicas y paleoecológicas en el debate de los homínidos del Pleistoceno Medio-Superior. British Archaeological Reports, International Series 979, Archaeopress. Oxford. 